\title{
DO APAGAMENTO À REVOLUÇÃO: O DIREITO DA CRIANÇA À CIDADANIA/DIREITO À CIDADE ${ }^{1}$
}

\author{
StUARt Aitken *
}

\begin{abstract}
RESUMO: Crianças e adolescentes estáo cada vez mais sendo colocados em posiçôes insustentáveis com relação ao seu direito de representação civil e seu acesso aos espaços públicos da cidade. Para solucionar tal impasse, eles geralmente tentam resolver os problemas por conta própria. Neste artigo, destaco o movimento dos Izbrisani na Eslovênia e a Revolución de los Pingüinos no Chile, por meio de ideias desenvolvidas por filósofos geopolíticos e teóricos que estudam o espaço, em combinaçáo com meu próprio trabalho acerca da formação política de jovens, para sugerir formas de re-imaginar a criança, o espaço urbano e a política.
\end{abstract}

Palavras-chave: Crianças. Juventude. Apagamento. Revolução. Direitos. Espaços na Cidade.

\section{FROM ERASURE TO REVOLUTION: CHILDREN'S RIGHT TO THE CITIZENSHIP/RIGHT TO THE CITY}

\begin{abstract}
Children and young people are increasingly placed in untenable positions with regard to their right to civic representation and their access to public city spaces. To resolve this impasse, they often take matters into their own hands. With this paper, I focus on the Izbrisani movement in Slovenia and the Pingüinos' revolution in Chile through ideas developed by spatial theorists and geo-political philosophers in combination with my own work on young people's political formation to suggest ways that children, urban space and politics can be re-imagined.
\end{abstract}

Keywords: City. Education. Children. Youth. Erasure. Revolution. Rights. City Spaces.

\section{D 'ANNULATION À LA RÉVOLUTION: LE DROIT DES ENFANTS À LA CITOYENNETÉ / DROIT À LA VILLE}

RÉSUMÉ: Les enfants et les adolescents sont de plus en plus placés dans des positions intenables en ce qui concerne leur droit civil à la représentation et

\footnotetext{
* San Diego State University, Department of Geography, San Diego, California, USA. E-mail de contato: saitken@mail.sdsu.edu.
} 
l'accès aux espaces publics de la ville. Pour sortir de cette impasse, ils essaient souvent de résoudre les problèmes sur leur propre. Dans cet article, je souligne le mouvement de Izbrisani en Slovénie et de la Revolución de los Pingüinos au Chili, grâce à des idées développées par les philosophes géopolitiques et théoriciens qui étudient l'espace, en combinaison avec mon propre travail sur l'éducation politique des jeunes, de suggérer des moyens de ré-imaginer l'enfant, l'espace urbain et de la politique.

Mots-clés: Enfants. Jeunes. Effacement. Révolution. Droits. Espaces de la ville.

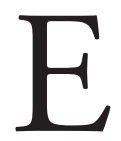

ste artigo coloca em foco a dimensão estética e política do ativismo de crianças e jovens nas cidades e explora as emoçóes que sustentam essas açôes ${ }^{2}$. Se os espaços forem considerados como eventos, e estes encorajam mudanças, então as relaçôes complexas reúnem espaços e jovens para que se tornem outro e, talvez, criar esperança. A ideia de jovens tornarem-se outro é um conceito provocante porque sugere que os caminhos traçados por adultos, por meio de, por exemplo, educação e deveres civis, podem não ser necessariamente os melhores caminhos para a próxima geração. Com isto em mente, este artigo versa sobre a projeção das posições e das vozes dos jovens marginalizados na arena pública. É uma tentativa séria de dar destaque aos contextos de crianças e jovens nas cidades face ao desenfreado neoliberalismo global, à privatização e às políticas revanchistas em relação àqueles que se encontram às margens. Como estudos de caso, foram desenvolvidos dois projetos de pesquisa, um centrado na Revolución de los Pingüinos no Chile (COLLEY; AITKEN, 2013; AITKEN, 2014, 2015) e o outro, nas crianças Izbrisani (os Apagados) na Eslovênia. (AITKEN, 2014) O objetivo político deste esforço está entrelaçado com o trabalho teórico que aponta para uma melhor compreensão das relaçóes entre os jovens e seu lugar no mundo. (AITKEN, 1994, 2001)

Neste artigo a perspectiva recai sobre os espaços de alteração e transformação como parte de uma análise crítica fundamentada nas teorias espaciais e geofilosóficas de Henri Lefebvre, Dorren Massey, Gilles Deleuze, Slavoj Žižek, Giorgio Agamben e Jacques Rancière. Com base nas referidas filosofias e teorias, argumento que os espaços da cidade são transformativos, na medida em que abrem o político para crianças e jovens. Esta perspectiva não é apenas sobre o espaço como um palco estático no qual os jovens ostentam suas coisas, mas, ao contrário, é sobre as práticas políticas, estéticas, econômicas, terapêuticas, sociais e culturais complexamente entrelaçadas que, simultaneamente, inscrevem os jovens nos lugares e os fortalecem. Se considerarmos os espaços como eventos e, se concordarmos que os eventos encorajam mudanças, entấo espaços e pessoas simultaneamente tornam-se outro através das complexas relaçóes ecológicas e emocionais. 
Ao longo do artigo tentarei descrever essas relaçóes de forma lírica e poética para não diminuir a importância das emoçóes e do afeto como um impulso político no mundo. Em debates mais amplos, no campo das ciências e humanidades, é nítido que as emoçóes importam; elas impactam a forma como sentimos o passado, o presente e o futuro, e nos ajudam a negociar eventos. $\mathrm{O}$ estudo das emoçóes, no que tange à geografia, tornou-se um importante esforço de pesquisa nas Ciências Sociais com especial enfoque em como elas explicam os contextos políticos, como ajudam a criar e recriar pessoas e espaços, e como afetam as formas como as pessoas imaginam seu lugar no mundo. (DAVIDSON et al., 2007) Teoricamente, o trabalho neste artigo deriva de uma compreensão pós-estrutural de afeto, emoção e estética, visto através da paralaxe do feminismo e do Marxismo.

\section{A política espacial de crianças e jovens}

Kallio e Häkli (2013, p. 1-2) sugerem que o estudo da política espacial de crianças e jovens se beneficiaria de uma melhor conceituação e consistência teórica. E, embora tudo possa ser tornado político, na infância como em qualquer outro aspecto da vida, os lugares da política são imprevisíveis e não podem ser conhecidos ou definidos fora de contexto; o espaço, portanto, tem importância. (KALLIO; HÄKLI, 2011) Com base nisso é possível argumentar que não somente os eventos no espaço são imprevisíveis, mas também os jovens são imprevisíveis em suas ações espaciais, e esta complexa interação entre a juventude e o espaço é perpassada por afetos emocionais que, por sua vez, impulsionam outras açóes e transformaçóes. Na medida em que há flexibilidade dentro das estruturas espaciais, então há a possibilidade de alteração e transformação para melhorar as vidas dos jovens. Isso suscita as seguintes questôes: o quê, exatamente, significa espaço e quem, precisamente, são os jovens?

Henri Lefebvre (1991, 1996), ao elaborar seu famoso manifesto em The Right to the City (O Direito à Cidade), apontou que o uso do conceito de 'espaço' como um contexto material, tanto no discurso popular quanto acadêmico, quase sempre se dá de forma ingênua. Usar um termo como espaço, defende Massey (2005, p. 17), chama um conceito "com a força implacável do óbvio patente" e, observa forçadamente, "este é o problema" com o espaço. Conceitos de espaço, lugar e escala são importantes demais para sugerir simples associaçóes Cartesianas e Euclidianas. Massey (2005, p. 19) sugere que quando o espaço, especialmente urbano, é usado em formas que se relacionam com conexóes banais, ele começa a ser associado com a formação de hábitos e dissociado de uma "completa inserção no político". Massey, ao contrário, abraça a insistência de Ernesto Laclau na conexão íntima entre deslocamento e a possibilidade de política. Para Laclau (1990), 
espacialização - por exemplo, ver o espaço como um container Cartesiano de atividades sociais - é equivalente a hegemonização: é uma forma de controle, um enquadramento das atividades em feixes organizados que são, então, passíveis de serem analisados de determinadas formas, como usar previsóes econômicas para predizer futuros congestionamentos em rodovias, ou usar elementos de design tais como residências com maior densidade ou com varandas, na esperança de criar um senso de comunidade. Enquadramentos espaciais tais como esses estão relacionados às estratégias institucionais de De Certeau (1984) e são produtos de encerramento ideológico, uma pintura do mundo deslocado como sendo, de certa forma, coerente. (MASSEY, 2005, p. 25)

Por mais de três décadas geógrafos e planejadores urbanos têm colocado o foco na ocupação do espaço por crianças e jovens. Nos debates atuais acerca do que constitui a infância e a juventude, a implicação de ter espaços para o desenvolvimento de crianças e adolescentes ganhou tração significativa. Esses debates morais e éticos sobre o tipo correto de espaços para as crianças ocuparem, neles crescerem e os recriarem está além do escopo deste trabalho (para uma revisão abrangente ver AITKEN, 2001 e HOPKINS, 2010), mas é importante que ao menos consideremos as relaçóes entre o caráter das crianças e o caráter dos espaços da cidade. Endossando tal perspectiva, Matthews e seus colegas (2000) observaram que é importante que crianças e adolescentes recuperem seus espaços nas ruas, argumentando que algo é perdido quando jovens são sequestrados para dentro de locais controlados por adultos e aparentemente seguros.

A seguir, apoiando-me nesses princípios teóricos de espaço urbano e infância, com um olhar específico voltado aos direitos e ao ativismo de jovens, apresento dois estudos de caso: as crianças Izbrisani (os Apagados) na Eslovênia e a Revolução dos Pingüinos no Chile. Metodologicamente emprega-se uma técnica por meio da qual as palavras dos jovens são transformadas em estrofes poéticas e diálogos, como uma forma de representar algumas das emoções que eles mostram durante as entrevistas realizadas por mim, outros acadêmicos e a mídia. Visto que pesquisas sobre emoções possuem agora grande participação nas Ciências Sociais, usar representaçóes poéticas ou líricas em artigos acadêmicos ajuda a destacar as formas como os jovens afetam as políticas públicas das ruas. (AITKEN, 2009, 2014)

\section{A poética do apagamento}

Durante os anos 1990, um segmento em particular da juventude eslovena desapareceu das ruas de Liubliana (Ljubljana), Maribor, Koper e outras áreas metropolitanas do país. O segmento era conhecido como os Izbrisani, uma população de mais de 25.000 residentes eslovenos que foram eliminados dos registros de 
residência permanente em 1991, e que perderam a oportunidade de se tornarem cidadãos ${ }^{3}$. A partir de 2009, as estatísticas oficiais enumeram que 5.360 (quase 21\%) dos Izbrisani tinham menos de 18 anos de idade. (KOGOVŠEK, 2010, p. 133) Estudiosos e ativistas locais defendem que os Izbrisani representam um caso único de fronteira administrativa realizada por meio de discriminação étnica e linguística e violação dos direitos humanos. (ZORN; LIPOVEC ČEBRON, 2008; KUHELJ, 2011) Obviamente, para os fins deste trabalho, o termo fronteira não se refere somente à língua e etnia. As crianças Izbrisani também são um caso especial em termos de 'fronteiras' que abrange inclusão versus exclusão, infância versus idade adulta, bem como racismo, discriminação de classe e cidadania. $\mathrm{O}$ que é particularmente interessante sobre o processo de apagamento para o contexto teórico que estou desenvolvendo aqui é que, primeiramente, muitas crianças Izbrisani foram transformadas em apátridas por decreto, em um círculo vicioso em que elas não tinham nenhum direito na Eslovênia e não podiam deixar o país para recolher a documentação necessária em outro local temendo não serem capazes de retornar. Em segundo lugar, as preocupaçóes centram-se em torno das relaçóes emocionais problemáticas, dentro da família e da comunidade, que a falta de um status legal engendra. Em terceiro lugar, e devido a isso, esses jovens desapareceram das ruas das cidades (e das escolas e comunidades) em virtude do medo de represálias e retaliações por parte dos cidadãos eslovenos legais e da possível deportação se eles fossem apreendidos pela polícia ou outros oficiais.

\section{Crianças apátridas desaparecem das ruas das cidades}

Na ocasião do apagamento judicial na década de 1990, muitas crianças Izbrisani tinham sua certidão de nascimento registrada na Eslovênia como sendo cidadãos de outras repúblicas Iugoslavas, mas, com frequência, as repúblicas em questão não haviam sido informadas do nascimento. Tendo em vista que o jus sanguinis (do Latim, literalmente, "direito de sangue") era usado para conceder a cidadania, não importava se essas crianças haviam nascido e vivido suas vidas inteiras na Eslovênia. Não apenas tinham seus direitos legais e estatuto legal negados na Eslovênia, como também não eram reconhecidas pelos antigos estados Iugoslavos. Com o apagamento dos registros eslovenos, os jovens que não eram reconhecidos como cidadãos pelos países de origem de seus pais perderam a conexão com o único país ao qual poderiam requerer cidadania por meio da naturalização. $\mathrm{O}$ apagamento fez surgir, como decorrência, crianças apátridas que temiam retaliações e deportação, e que aprenderam, por consequência, a desaparecer das ruas das cidades.

As consequências diretas de perder o status e a presença urbana durante o processo de apagamento incluíram a perda do seguro de saúde, do emprego, nenhuma possibilidade de comprar um apartamento que não fosse a preços co- 
merciais, nenhuma possibilidade de continuar os estudos ou de dirigir um carro legalmente. Outros fatores incluíram a exposição diária à conduta arbitrária de policiais e burocratas, limitando, portanto, a livre movimentação pelas ruas da cidade, bem como a privação de acesso a informação. Esses contextos de apagamento, algumas vezes, apareciam como restriçóes e repreensóes, como detenções e expulsóes ou como negação ao acesso a informaçóes em processos que pareciam arbitrários e movidos pelo capricho de burocratas. O que é patente, como algumas das estórias dos mais de 5.000 jovens atingidos por esse processo revelam, é o efeito sistemático no seu bem-estar emocional e em seu desenvolvimento.

Aprender a como desaparecer das ruas da cidade era uma tática comum para as crianças apagadas. Um jovem apagado - cuja estória foi publicada em KOGOVŠEK et al. (2010, p. 79-81) - que tinha 11 anos em 1992, relata como cresceu em Fužine, um bairro urbano da classe operária com uma grande proporção de imigrantes ao leste do centro de Liubliana, sob o que ele sentia ser uma vigilância constante da polícia. Mesmo em tão tenra idade ele compreendia a necessidade de permanecer invisível às autoridades nas ruas urbanas. Ele encontrava formas de ir e vir da escola evitando passar por viaturas da polícia. Por 10 ou 11 anos ele manteve sua cabeça baixa ao andar em Liubliana e recusava convites para viajar para a costa da Croácia e da Bósnia porque não tinha os documentos que permitiriam que ele retornasse para sua casa em Fužine. Mas tudo isso implicava muito mais do que náo poder viajar para a praia com seus amigos:

\author{
Eu sentia falta da praia, da minha avó. \\ Minha avó na Bósnia, \\ onde costumávamos ir nas férias, \\ era bem velhinha, \\ e eu sempre quis que ela vivesse, não morresse, \\ para que eu pudesse vê-la novamente. \\ Meu avô morreu em 1994, mas eu não pude ir ao \\ funeral - \\ Isso foi muito difícil para mim. \\ Nós estávamos trancados neste país. \\ (Anônimo, estória de um jovem apagado, excerto \\ de KOGOVŠEK et al., 2010, p. 80)
}

Embora fosse difícil para muitas crianças compreenderem as privaçóes específicas que o apagamento implicava, a maioria compreendia, em certa medida, que eles estavam sendo selecionados para tratamento desigual. Eles também tinham a percepção de que seu contexto era bem sério e, para alguns, como veremos 
adiante, foi um incitamento à ação que contrastava com sua tenra idade. Para outros era uma dura fronteira incongruente que eles não sabiam como transpor.

Giorgio Agamben (1993) mostra como o espaço do sujeito é alterado quando lhe é arrancada a bios politikos (vida política) e resta-lhe somente a $z o \bar{e}$ (a vida biológica ou a mera existência biológica). Considerando o trabalho de Agamben para o contexto dos Izbrisani, fica claro que um processo físico e emocional debilitante ou a negação aos direitos é também um processo biopolítico por meio do qual um grupo de pessoas foi despido de tudo, exceto da mera vida biológica. (ZDRAVKOVIĆ, 2010; LIPOVEC ČEBRON, 2011) A ideia de ser despido e restar somente a vida nua, levanta questóes acerca do que resta, não apenas da dimensão política mas também das habilidades de participar das responsabilidades cívicas e da vida nas ruas. Para os jovens que estão se aventurando no mundo da adolescência e experimentando os valores dos adultos, a vida nua compreende um sério conjunto de privações em uma época de formação. As consequências emocionais dessas privaçóes se apresentam nas açóes dos adolescentes, como delinquência, mau comportamento e mesmo suicídio, resultando em enormes consequências para as famílias e para as comunidades.

Indira relembra como foi difícil para seus filhos após terem sido apagados. O pai deles foi embora e ela se tornou o único provedor da família. "Foi difícil para as crianças sem ter os documentos", ela relembra, "Eu chegava em casa; o mais velho estava tão ... nervoso. Eu chegava cansada, só querendo me deitar, e ele estava nervoso. Ele dizia que não era como as outras crianças, e ele não era nada e não podia fazer nada com os seus amigos". (excerto de KOGOVŠEK, 2010, p. 129) Para os jovens, a perda do status é sentida como uma forma de othering (alteridade) que pode arrancar-lhes qualquer vestígio de dignidade em um período em que estão buscando identidades coerentes, que sejam adequadas àquilo que desejam se tornar. Sentir-se para baixo e sentir-se "como nada" facilmente leva a formas mais sérias de depressão.

Eu também pensei em suicidio.

Doeu quando eu tive que comprar documentos falsos, roubados, para poder me locomover livremente.

Eu paguei 500 marcos alemáes por uma carteira de motorista.

(Jansa, 45 anos de idade, extraído de KOGOVŠEK, 2010, p. 103)

Esses excertos poéticos, produzidos a partir dos relatos dos jovens apagados, revelam um contexto extremamente emocional devido a algumas formas em que a vida nua é indelevelmente entalhada na psique e transparece nos corpos 
jovens. Esta luta contra a mera existência é uma tentativa, em uma variedade de níveis, por parte de um grupo social oprimido e desempoderado, de desempenhar um papel na política de reprodução espacial e place-making [N.T.: A tradução literal "criação de espaços"]. O poder institucional (a negação dos documentos), as práticas materiais (o roubo de documentos), as emoçóes pessoais ("Eu chorei tanto") e as relaçóes sociais ("foi difícil para as crianças") influem no grau de investimento de um lugar e o conflito ocorre quando um grupo social é forçadamente distanciado, deslocado ou incapaz de ter uma voz na reprodução espacial e place-making: este conflito constitui o direito à cidade e a luta para permanecer no lugar. (LEFEBVRE, 1996; CURTI et al. 2013)

Em uma luta contra o apagamento e a vida nua, muitos jovens assumiram a tarefa de se registrar para obter um status legal na Eslovênia. Esses atos presumidamente não infantis (AITKEN, 2001) pressagiam uma responsabilidade que vai além das expectativas sociais em relação a crianças e adolescentes em outros locais. De formas importantes, os casos dos Izbrisani são ainda mais imperativos porque sua luta para permanecer é uma luta não apenas por status legal e direito à educação e à saúde, e de poder andar livremente pelas ruas das cidades, mas uma luta por uma raison d'être em seu próprio local de nascimento.

Em 1992, eu ainda não tinha nem 11 anos.

A gente esperou impacientemente pelo carteiro

que trouxe um convite para a minha irmá ir à unidade administrativa.

Ela arrumou seus documentos pessoais lá.

Dois meses depois eles a chamaram novamente para ir à unidade administrativa

e trazer os seus novos documentos

Desta vez eles tiraram os documentos delaos mesmos que eles haviam emitido dois meses antes os perfuraram e disseram que não eram mais válidos.

Eu me lembro do dia em que ela chegou em casa, ela estava muito triste, ela chorou, a minha irmá; ela tinha 15 anos na época e ela estava cuidando dos documentos sozinha.

(Anônimo, estória de uma pessoa apagada, extraído de KOGOVŠEK et al., 2010, p. 79)

Tendo em vista que as relaçôes do Estado esloveno com os Izbrisani eram manifestas em medidas burocráticas arbitrárias, que impactaram tanto 
a psique como os corpos, parece ser razoável evocar interpretações teóricas dos pontos de vista da "esquizo-e-bio-políticas". Essas são políticas que focalizam a natureza esquizofrênica dos espaços da burocracia contemporânea e da cidade (DELEUZE; GUATTARI, 1988) por meio das quais alteraçóes dramáticas tais como o apagamento são tanto imprevisíveis como lugar comum. A esquizofrenia e a incerteza que cercam a política contemporânea também ressaltam processos por meio dos quais alguns segmentos da população não são apenas marginalizados, mas reduzidos à vida nua. Slavoj Žižek $(2008,2010)$ faz algum progresso em direção à elaboração de uma crítica da percebida dissimulação da sistemática e objetiva violência do estado, central ao sistema capitalista neo-colonialista, ao destacar um ocultamento que é formado, em grande parte, pela despolitização dessas supostas representaçóes esquizofrênicas de diferença enquanto, ao mesmo tempo, arrancando da oposição qualquer semblante de vida política - o que Agamben (1993) chama de bios politicos. Zdravković (2010, p. 259) destaca o ponto em que (e que perdurou por mais de uma década), as pessoas apagadas foram despidas de tudo, exceto da mera vida biológica, por sucessivos governos que os representavam como indivíduos que eram "espertos", "desleais" e "calculistas"; indivíduos que estavam tentando enganar o sistema para obter direitos e privilégios aos quais não se qualificavam. Pistotnik (2010) discorre sobre as formas como os apagados eram tidos como antipatriotas, ao passo que Beznec (2008, p. 16) destaca as formas com que foram representados como "agressores na Eslovênia, especuladores na cidadania e aproveitadores sanguinários”.

Em uma abordagem deleuziana, Žižek (2010) argumenta que eventos como o apagamento são lugares potenciais para a repolitização radical de determinados impasses sociopolíticos. Se concordarmos que dentro do modo capitalista de produçáo a representação funciona simplesmente como um meio de coordenar os fluxos de poder que são hierarquicamente organizados, então, talvez, uma nova política de criatividade e "biopoder" - por exemplo, a "esquizopolítica" de Deleuze e Guattari (1998) em que grupos marginalizados usam a esquizofrenia política em seu benefício - é possível; uma que pode criar novos padróes de expressão e de ser. A luta dos Izbrisani por representação sugere tal padrão de repolitização radical. A seguir, discuto isso por meio da lente da "biopolítica" de Agamben (1993) e introduzo a estética radical de Rancière (2009, 2010).

\section{A luta dos Izbrisani por representação e justiça e direitos de ocupar o espaço}

Há dignidade e integridade em se juntar em torno de uma causa comum e da memória coletiva. Ismeta estava na faixa dos 20 anos quando se juntou à luta pelos Izbrisani por intermédio da Associação dos Residentes Apagados: 
Um dia eu ouvi na TV sobre a Associação dos Residentes Apagados.

Eu não fazia ideia de que havia tanta gente apagada

Oh céus, quando nós começamos a conversar...

Eu me senti como se tivesse asas.

Como se uma pedra tivesse caido do meu coração.

As dores literalmente começaram a descascar meu corpo.

Eu podia sentir vida, saúde, o futuro.

Eu podia ver a luz no fim do túnel.

(Ismeta, 49 anos, refletindo sobre quando estava na faixa dos 20 anos. Excerto de ZORN,

$$
\text { 2010, p. 23) }
$$

Zorn (2010) destaca que a memória coletiva é necessária, em primeiro lugar, para galvanizar as experiências individuais e, as estórias, por conseguinte, produzem uma memória coletiva como um

[...] filtro seletivo que reconstrói as memórias com base naquilo que é necessário no momento [...] A narrativa de experiências pessoais em eventos públicos organizados pelas pessoas apagadas pôs um fim ao silêncio público [...] criou uma memória coletiva na qual o apagamento figura como um evento ilegítimo, ao mesmo tempo em que contesta o etnonacionalismo fundado na burocratização dos direitos. (ZORN, 2010, p. 24)

Com o reconhecimento ocorre, em uma segunda instância, um chamado para a ação, para o movimento, para a força social, para uma arremetida em direção aos direitos e reparaçóes.

Se a tua mente não enlouquece

tudo sorrateiramente se move para os outros

$$
\text { órgãos... }
$$

Todo aquele sentimento de não pertencer.

$$
\text { A qualquer lugar. }
$$

Tudo isso deixa consequências.

Mas agora,

eu recuperei um pouco da minha autoconfiança. 
Eu não fico mais esperando acuada em um canto.

Essas viagens pelo mundo como uma ativista me fizeram levantar.

Eu digo a mim mesma: Eu não sou um lixo.

Essas viagens me deram tanto.

Eu me lembro de pessoas felizes, jovens, despreocupadas.

$O$ ativismo me deu grande força e autoconfiança.

(Marjana, 46 anos, relembrando seus 20 anos, excerto de LIPOVEC ČEBRON, 2011, p. 270)

O ativismo, bem como uma redefinição do trabalho envolvido nas responsabilidades cívicas, aponta não somente para uma redefinição dos direitos entendidos de forma ampla em termos das múltiplas relaçóes e diálogos com a sociedade (MOOSA-MITHA, 2005), mas também para uma nova e revigorada estética política.

O trabalho de Jacques Rancière $(2009,2010)$ sugere a possibilidade de levantes populares espontâneos, por meio de uma compreensão pós-estrutural da estética. A visão de Rancière sobre a estética vai além das ideias tradicionais de beleza, paisagem e sensibilidades artísticas e avança em direção à consideração da "partilha do sensível” (RANCIÈRE, 2009, p. 1) em termos das relaçôes “[...] entre o que as pessoas fazem, o que elas vêem, o que elas ouvem e aquilo que conhecem". (RANCIÈRE, 2010, p. 15-17) De forma semelhante à noção de deslocamento de Laclau (1990) e da noção de surpresa de De Certeau (1984), Rancière argumenta que a política ocorre quando há uma ruptura em um mapeamento hegemônico e dominante do sensível. Para os Izbrisani havia uma ruptura radical da identidade como consequência de restar-lhes a mera vida biológica, por meio de um processo que teve início em 1991 e levou a um estado de exceção (AGAMBEN, 1995, p. 9) por intermédio do qual eles podiam ser apagados. David Marshall (2013) sustenta que essas estéticas políticas radicais e relacionais residem de forma mais potente entre os jovens. Marshall (2013, p. 54) usa Rancière para destacar

[...] como nós podemos compreender o momento político presente por meio das vidas das crianças e como as crianças possuem um papel em construir futuros alternativos [...] como as crianças tanto desempenham quanto transformam a estética do sofrimento.

Para Marshall, as rupturas do sensível pelos jovens transparece em sua arte e brincadeiras, mas eu gostaria de discordar, com base nas ideias de Kallio e Häkli $(2011,2013)$ a respeito da política das crianças em seu dia a dia, da vigorosa 
declaração de Staeheli et al. (2013) de que não existe apenas a estética radical em jogo, mas também o ativismo dos jovens e seu direito à cidade.

A narrativa dos Izbrisani como sendo espertos, manipuladores e não patriotas é quebrada quando a Associação de Pessoas Apagadas é criada e, em 2002, começa a colher estórias e transcrever as experiências e memórias dos apagados para disponibilizá-las ao público. Então, em 2005 a Iniciativa Civil dos Residentes Apagados foi organizada e tornada pública através de uma série de greves de fome. As greves de fome tiveram início na fronteira da Croácia e se moveram para a sede da Unicef em Liubliana para chamar a atenção do público para as 5.000 crianças que haviam sido apagadas. Embora não houvesse nenhuma criança participando das greves de fome, eles levantaram a questão de que a cidadania deve ser examinada em termos de relaçóes interdependentes ao invés de meramente em termos de direitos autônomos. Moosa-Mitha (2005) redefine os direitos das crianças ao examinar se as crianças são capazes de exercer uma presença nas muitas relações das quais participam. O sentido que a autora confere à presença é: até que ponto a “[...] voz, contribuição e agência das crianças é reconhecida”. (MOOSA-MITHA, 2005, p. 381) As greves de fome dos Izbrisani na Unicef proclamaram a presença dos jovens entre os apagados. Presença, mais do que autonomia e individualismo, define o "eu-cidadão" (citizen-self) em relação às famílias, instituições e nas ruas.

Balibar (2004) descreve a Europa, com referência especial à Eslovênia:

[...] como um 'laboratório democrático', uma justaposição de 'locais de trabalho' onde novos aspectos da democracia são necessários e talvez passíveis de serem desenvolvidos, algo que poderia ser significativo não apenas localmente, mas também de modo geral, ou globalmente.

Mandelc e Učakar (2011) descrevem a Eslovênia como uma "democracia perfurada" e argumentam, na linha de Rancière (2010), que os direitos humanos advêm de comunidades políticas onde a cidadania é defendida em termos de ações, presença e opiniōes, ao invés de direitos de nascença. A estética eslovena tem o potencial de desenvolver novas formas de compreender a democracia e a cidadania ao focalizar a atuação das crianças Izbrisani como atores que estão sempre presentes e, geralmente, declaradamente políticos, e cujas relações cotidianas com o espaço, outros atores e instituiçóes define seu status civil.

Relatando sobre as crianças Izbrisani, eu elaboro as condiçóes de ser apátrida, da mera existência biológica e da presença, que conduzem a uma ruptura estética nos espaços civis, urbanos e, essencialmente, nos espaços políticos. Nas próximas seçôes, eu uso a Revolução dos Pingüinos para examinar as maneiras pelas quais os jovens retomam as ruas e outros espaços públicos para protestar por mudanças no direito específico à educação. Na medida em que o sucesso dos 
Izbrisani deve ser atenuado pelo sofrimento emocional dos jovens causado pelo apagamento, a Revolução dos Pingüinos - embora também com suas desventuras - sugere uma forma completamente diferente de retomada dos direitos civis e do espaço urbano por parte dos jovens.

\section{A Revolução dos Pingüinos}

Na primavera de 2006, os estudantes no Chile tomaram as ruas e ocuparam escolas de Ensino Médio em Santiago, Valparaíso e outras cidades para protestar contra a contínua privatização da educação e a crescente disparidade entre alunos ricos e pobres. Em poucas semanas os protestos cresceram de uma simples marcha em Santiago para uma campanha nacional que colocou metade das escolas no Chile em greve ou sob ocupação. Os protestos atingiram seu ápice em 30 de maio, quando 800.000 estudantes foram às ruas. Sua rápida mobilização, por meio de mensagens de texto, pegou as autoridades de surpresa e este é, geralmente, considerado o primeiro protesto no mundo a ser ativado via mídias sociais. (REEL, 2006) O protesto ficou conhecido como a Revolução dos Pingüinos devido aos uniformes preto e branco (e algumas vezes as carteiras escolares) que encheram as ruas urbanas. Tendo em vista que os jovens estudantes estavam fora de seu lugar, protestando nas ruas vestindo seus uniformes escolares, eles perturbaram o sensível no sentido formulado por Rancière (2010) quando descreve a ruptura da estética de lugar comum. Conforme observado anteriormente, o trabalho de Rancière trata da ruptura espaço-temporal dos sentidos, embora ele não defenda a sensação como algo necessariamente político. Pelo contrário, é por intermédio da ruptura das sensibilidades hegemônicas, por meio do deslocamento (LACLAU, 1990) e da surpresa (DE CERTEAU, 1984), que o político emerge. O movimento dos Pingüinos tornou-se uma revolução política quando reivindicou uma ética radical, que era sobre a distribuição das percepções e capacidades em relação às posiçốes dos jovens na sociedade. (ŽIŽEK, 2010) A estética de Rancière (2010, p. 19) é sobre rupturas na ordem ética e sua subversão. A estética se torna a expressão de uma ideia política que é perturbadora à primeira vista, mas então, em um segundo momento, elabora a ideia de um outro futuro e de um outro lugar. (RANCIÈRE, 2005, p. 80) Ao observar isso, Marshall (2013, p. 57) aponta que novas possibilidades

[...] emergem entre o espaço físico [isto é, as ruas das cidades] que é percebido pelos sentidos e o espaço discursivo que ordena nossas formas de ver e de fazer. É essa ruptura estética que permite novas possibilidades de ver e de fazer.

Allison Bakamjian (2009, p. 2) observa que 
[...] havendo tentado alterar as políticas de privatização de escolas por intermédio de recursos políticos mais formais no passado, os estudantes acreditavam que um levante em massa [nas ruas] era a única maneira de conseguir atenção suficiente do governo para fazer alguma diferença.

A habilidade dos estudantes em articular uma rápida mobilização por meio de mensagens de texto não tinha precedentes naquilo que Bakamjoan chamou de uma era democrática amplamente "desmobilizada" no Chile. O que ela quer dizer é que, por mais de uma década houve relativa estabilidade no Chile, com apenas pequenos protestos e passeatas nas ruas depois de várias décadas de intranquilidade. A ditadura de Augusto Pinochet havia terminado em 1993, anunciando o que parecia ser uma nova era da democracia que náo requeria mobilizaçóes ativistas e, assim, as crianças e os jovens haviam crescido sem vivenciar protestos de rua. Mas, em 2006, o legado da privatização do sistema educacional realizado na era Pinochet - que tipifica a natureza baseada no mercado das reformas políticas econômicas e sociais dessa época - permaneceu como um toque de clarim para muitos alunos, especialmente aqueles das áreas menos privilegiadas, para tomar as ruas em defesa de um sistema educacional mais justo. Os paralelos com o apagamento na Eslovênia são bastante espantosos, na medida em que ambos ocorreram em países com histórias de ditadura que terminaram a favor de governantes eleitos democraticamente. Uma compreensão disto requer uma elaboração mais aprofundada dos princípios econômicos neoliberais abraçados por países que se tornaram democráticos mais recentemente como a Eslovênia e o Chile.

De acordo com David Harvey (2005, p. 39) o neoliberalismo nasceu no Chile quando o golpe militar de Pinochet, com o apoio dos EUA, removeu o governo Allende que havia sido democraticamente eleito. A inclinação de Salvador Allende em direção ao socialismo foi destruída nesse violento golpe, no qual ele faleceu, e foi substituída por um modelo econômico baseado no trabalho de Milton Friedman (1962) e seus alunos da Universidade de Chicago. Harvey (2005, p. 8) destaca que desde os anos 1950, os economistas chilenos recebiam financiamento da Universidade de Chicago por intermédio dos EUA como parte de um programa contra ideologias de extrema esquerda durante a Guerra Fria. Pinochet trouxe alguns desses jovens economistas neoliberais para o seu governo para prescrever uma nova estrutura ideológica para seu bravo mundo novo. Trabalhando em conjunto com o Fundo Monetário Internacional (FMI), eles reestruturaram a economia chilena em torno de suas teorias do capitalismo neoliberal. Harvey também enfatiza a curta duração da reviravolta econômica chilena - particularmente com a crise da dívida em 1982 - mas as políticas estavam em vigor e continuaram após Pinochet. Com o tempo, os processos se moveram, implacável e consistentemente, em direção ao doutrinarismo social de direita. Uma agenda 
mais ampla de doutrinarismo social foi defendida por aqueles que mais poderiam obter lucros; os políticos eleitos, em especial, tinham um interesse econômico na privatização das escolas:

\section{Se você quiser se desenvolver enquanto ser humano, você precisa aprender,} estudar.

Você tem o direito de frequentar a universidade.

Desde o inicio, nossa principal demanda era de que

$$
\begin{aligned}
& \text { o estado deveria pagar } \\
& \text { os custos da educaçáo. }
\end{aligned}
$$

No Chile a educação é um negócio importante.

Imagine, desde os anos 1990, nunca houve um

$$
\text { ministro ... }
$$

... que também não fosse proprietário de uma escola.

A educação nunca esteve na agenda dos políticos.

Mas, em 2006 essa situação foi colocada de ponta cabeça.

(Maria Jesús Sanhueza, líder estudantil chilena, 2012)

Os jovens que mais estavam em risco a partir desse colapso, os jovens que mais tinham o que perder, as pessoas incapazes de votar ou de ter acesso ao processo democrático de qualquer forma significativa devido à sua idade, tomaram as ruas para pressionar por mudanças profundas.

\section{Levando as salas de aula para as ruas}

No cerne das demandas dos Pingüinos estava uma completa reestruturação do sistema educacional privatizado, que eles consideravam antidemocrático e socialmente injusto. $\mathrm{O}$ evento que inflamou as primeiras marchas de protesto em abril de 2006 foi o anúncio do aumento de custos para fazer a Prueba de Seleccion Universitaria (PSU), que muitos alunos achavam que deveria ser gratuita para aqueles da classe socioeconômica mais baixa. A primeira marcha contava com alunos de 15 escolas de Ensino Médio em Santiago, mas rapidamente tornou-se um evento a nível nacional. A ocupação da primeira escola ocorreu em Santiago, em 19 de maio e, uma semana depois, 100 escolas pelo país se juntaram ao movimento de ocupação e uma greve nacional por tempo indeterminado do sistema de ensino foi declarada. Alunos de algumas das escolas mais prósperas declararam 
solidariedade e também se juntaram às ocupaçóes e marchas. Mesmo quando o movimento decolou, as autoridades governamentais continuavam a negar um encontro com os estudantes.

Então, em 21 de maio, a recém-eleita presidente Michelle Bachelet [N.E.: Verónica Michelle Bachelet Jeria, 48a. presidente do Chile, período de 11 de março de 2006 a 11 de março de 2010] declarou que o movimento era antidemocrático. (BACHELET, 2006) ${ }^{4}$ Uma semana depois, o Ministro da Educação, Martin Zilic, concordou em se reunir com os estudantes, mas, ao invés disso, enviou sua subsecretária. Sentindo que não estavam sendo levados a sério, os estudantes novamente se mobilizaram e, em 30 de maio, apenas um dia após a fracassada reuniáo com Martin Zilic, aproximadamente 800.000 estudantes por todo o país retomaram às ruas e às escolas. $\mathrm{O}$ protesto continuou por mais de uma semana enquanto os estudantes negociavam com um ministro mais atento. A demanda básica do movimento era a reestruturaçáo do sistema escolar descentralizado baseado no mercado, que incluía isenção de taxa de inscrição para fazer a PSU, e transporte público gratuito para todos os estudantes. Uma semana depois, a presidente Michelle Bachelet fez um pronunciamento público, em rede nacional de televisão, dirigindo-se aos Pingüinos e afirmava: "Nós reconhecemos que as suas demandas são justificadas e razoáveis. Assim, a partir deste ano nós concederemos, a todo estudante que assim o necessitar, uma bolsa de estudos". Após três meses de luta, com muitas de suas demandas atendidas e com a criação de um Conselho Assessor Presidencial de Educação com representação estudantil, o movimento dos Pingüinos desfez-se e as aulas foram retomadas com a condiçấo de que o governo seguisse adiante e cumprisse suas promessas.

A Revolução dos Pingüinos é um exemplo de pressão política efetuada por jovens que são muito novos para votar, mas são capazes de ativar conectividades sociais massivas para retomar as ruas. (COLLEY e AITKEN, 2013) Como observa Bakamjian (2009, p. 18),

[...] eles estavam insatisfeitos com as ambiguidades das políticas, entre o autoritarismo e a democracia, que infestava a sociedade na qual haviam crescido, e eles reconheciam a urgência de alterá-las [...]. A crença dos estudantes na verdadeira democracia é evidente pelo propósito do movimento, a maneira pela qual eles o executaram e a organizaçáo dentro do movimento.

A revolução é notável na medida em que os jovens não tinham um modelo de protesto de rua e o uso de mídias sociais impulsionou um movimento contra o qual o governo náo pode reagir oportunamente. Sugere a possibilidade de retomar o direito à cidade através das mídias sociais por parte de uma grande 
faixa da sociedade que não está envolvida em processos políticos e o status quo, e que não vota.

A Revolução dos Pingüinos é notável, portanto, na medida em que é constituída por um amálgama de jovens que não tiveram nenhum modelo de protestos de rua, alguns que tinham vivenciado a resistência em segunda mão, somente por meio das experiências de suas famílias e, ainda outros, que haviam se conscientizado, por intermédio de sua educação, a se mobilizar contra um sistema e um regime que não esperava resistência. Prosseguindo da estética e perturbação do sensível de Rancière $(2005,2010)$, a revolução é um exemplo palpável do ato ético radical de Žižek (2010, p. 326), porque encerra a mudança entre os jovens primeiro internamente, através deles mesmos, suas famílias e seu sistema escolar e, então, mudanças nas atitudes das autoridades em relação à sua situação. A invectiva, paixão e velocidade do levante dos Pingüinos sacudiram o governo de sua complacência, e foi uma combinação de deslocamento e surpresa que propiciou um impulso político adequado. (DE CERTEAU, 1984; LACLAU 1990)

As questóes suscitadas pela Revolução dos Pingüinos ricocheteiam entre organização interna, contrarrepresentação, ocupações, marchas nas ruas e a paixão dos estudantes. Conferências de imprensa eram agendadas de forma a ocorrer exatamente antes do horário nobre dos programas de televisão e as resoluçóes eram transmitidas diretamente para todo o país por meio das mídias sociais. As ocupaçóes das escolas eram coordenadas através de telefones celulares e e-mail e fotografias eram enviadas à mídia e colocadas na Internet. Ao agir assim, os estudantes criaram um público que testemunhava os eventos e que ficou emocionalmente conectado com as paixóes dos jovens. (COLLEY e AITKEN, 2013) À medida que as notícias iam se espalhando e uma presença on-line era mantida, o número de protestantes mais do que triplicou. Em termos de público, os Pingüinos receberam cobertura das páginas na Internet pertencentes a organizações não governamentais internacionais (ONGs), ganharam o apoio de organizaçóes sindicalistas e de alunos de escolas particulares que, em apoio, também saíram às ruas para protestar. As Naçóes Unidas (em especial o Unicef) entrou em contato com o governo chileno para expressar suas preocupaçóes com os direitos dos jovens. $\mathrm{O}$ movimento foi fortalecido por outros movimentos sociais no exterior.

O legado dos Pingüinos estava fundado nos problemas do sistema educacional local - embora a privatização neoliberal esteja agora se mostrando por todo o mundo e esteja causando problemas específicos nos EUA, Inglaterra e Suécia -, mas também representa ramificações de uma redução à mera vida biológica de Agamben (1993), no sentido de que a privatização da educação estava reduzindo as experiências escolares chilenas a um mero modelo de "prestar exames" que fazia pouco mais que mitigar as aspiraçóes do sistema de mercado global (RAVITCH, 2013) e os mais pobres eram marginalizados ou simplesmente eliminados da maior parte das oportunidades educacionais. 
O que isso sugere é que o movimento dos Pingüinos é, ao mesmo tempo, interno e externo; simultaneamente espaço físico e virtual, nas ruas e na Internet, e é ilustrativo das materialidades equivalentes e interconectadas, e das potencialidades virtuais de tornar-se por meio das famílias, tornar-se por consenso, tornar-se on-line e tornar-se nas ruas; esses não são mundos separados ou meramente transicionais, pelo contrário, na sociedade contemporânea eles são co-constitutivos dos interesses públicos que representam. Após três meses de luta, os Pingüinos ganharam concessóes do governo Bachelet, mas o que é importante aqui é que eles começaram com turbulência e surpresa, angariaram um amplo público e prosseguiram no sentido de se tornarem narradores de sua própria história.

Os Pingüinos, muitos dos quais agora estão na Universidade, continuam sua luta. Todo ano, nas férias de verão, eles tomam as ruas. Nos últimos anos os protestos se tornaram carnavalescos; repletos de fantasias e dança sincronizada. A cada ano, o governo cede um pouco em relação a um novo conjunto de demandas, ao mesmo tempo em que resiste ao completo desmantelamento do sistema educacional neoliberal. Na primavera de 2013, uma nova geração de estudantes ocupou escolas em Santiago para protestar contra a continuada desigualdade e o aumento de custos. Em grande parte, atualmente os protestos estudantis no Chile causam distúrbio, mas não são violentos. A resposta do governo quase sempre se dá por meio de gás lacrimogêneo e canhões de água. Em grande parte, tanto aqui como em outros lugares, a violência é mais insidiosa, conforme sugere Maria Jesús Sanhueza, uma das líderes dos Pingüinos originais:

As nossas açôes eram eclipsadas pela violência bruta,

então a única coisa que a gente podia fazer era ocupar as escolas.

Mas para nós, o que era realmente violento ...

... pior do que os cassetetes da polícia, era ...

que você não tinha nenhum direito à educação.

Eu chamo isso de uma forma extrema de violência.

Que se você nasce em algum lugar...

... você já sabe onde se encontram as fronteiras.

Que você náo pode estudar.

Um escravo não podia imaginar um mundo sem escravos.

Isso era um sonho.

Nós podemos não realizar nosso sonho, Mas esta utopia torna o amanhã possivel.

(Maria Jesús Sanhueza, líder estudantil chilena, 2012) 
É importante que os jovens nos surpreendam; que eles desloquem a nossa complacência e consigam enfurecer-se contra o status quo. É particularmente importante, agora, que eles consigam expressar uma opinião acerca das reformas educacionais neoliberais que têm como alvo os seus futuros. O exemplo da revolução dos Pingüinos sugere um ato ético radical importante através do qual os jovens mudaram algo dentro de si mesmos e, ao fazê-lo, essencialmente transformam a sociedade.

\section{Conclusão}

Crianças e jovens são cheios de surpresas. Eles vêem coisas em locais e ambientes que nós podemos ter esquecido de como ver, quanto mais compreender. Pode-se argumentar que eles possuem um senso inato de justiça e possuem a capacidade de perturbar a complacência dos adultos para com sistemas injustos. É minha convicção sincera de que é a partir desta percepção que lugares melhores e tempos esperançosos emergem. Este artigo examinou a evolução de nossas formas de pensar e conhecer os jovens e as políticas espaciais peculiares que guiam a maior parte das formas como nós e os jovens nos colocamos nas ruas das cidades. $\mathrm{O}$ que eu passei a acreditar é que existem poderosas inscriçóes emocionais em relação a esse ato. É sobre, em primeiro lugar, a simples presença dos jovens na ocupação do espaço. Se nós considerarmos o espaço como um importante arauto do político, bem como um importante produto do político, então a lição de Laclau, De Certeau, Massey e Rancière é de que deve haver um deslocamento, uma libertação da cartografia como um enquadramento de possibilidades, em direção a uma espacialidade material que é fluida e aberta a surpresas. Se seguirmos Žižek e Agamben, então esse deslocamento decorre da exegese da biopolítica como a mera vida biológica. Essa formulação de nenhuma forma abranda a interação concreta entre cidades, comunidade, identidade e a sociologia da infância; simplesmente os torna menos rigidamente atados à ciência, ao capitalismo, ao governo e outros quadros institucionais. Ao observar isso como uma forma particular de contextualizar a política, ela fornece uma especificidade para reconhecer as crianças como agentes políticos cujas vidas estão fundadas em um tipo específico de espaço urbano vivido.

Com os fundamentos geo-filosóficos deste artigo, e por intermédio de exemplos como o dos Pingüinos e das crianças Izbrisani, adentro questóes relativas às responsabilidades civis e ao ativismo de jovens e aos modos pelos quais podem ser reconhecidos por meio de novas formas de cidadania que são relacionais e valorizam por meio da diferença, e como podem recuperar o direito às ruas. É bastante claro que os conceitos de criança, jovem e de político não precisam ter significados 
estabelecidos e generalizáveis, mas é importante reconhecer que o político é inseparável da vida urbana e que crianças e jovens são uma parte inseparável dela.

\section{Notas}

1. As ideias e exemplos neste artigo podem ser encontrados, de forma mais elaborada, em Aitken (2014, 2015). Tradução realizada por Karin Quast. Revisão de tradução realizada por Fernanda Müller.

2. O artigo usa os termos crianças e jovens/adolescentes de forma intercambiável, embora o segundo se refira a adolescentes e mesmo aqueles na faixa dos 20 anos, e o primeiro se refira a pré-adolescentes. O motivo de misturarmos essas demografias é reforçar uma política que inclua tanto a infância como a adolescência, embora se mostre de forma diferente em cada caso. (KALLIO; HÄKLI, 2013) Ignorar a presença de crianças bem pequenas, por exemplo, é uma forma de opressão. (MOOSA-MITHA, 2005) Embora a política mude conforme as crianças se tornam adolescentes e tenham a capacidade para o ativismo, há, todavia, uma estética política palpável tanto para as crianças como para os adolescentes/jovens. (AITKEN, 2014)

3. Oficialmente o número de pessoas "apagadas" é 25.671, com base nos dados do Ministério do Interior da Eslovênia, mas algumas estimativas indicam um número superior a 35.000, principalmente sérvios, croatas e bósnios (mas também os rom e grupos eslovenos étnicos). Cerca de 11.000 apagados agora possuem status oficial na Eslovênia, alguns casos ainda estáo em julgamento e os restantes deixaram o país (comunicação pessoal com um advogado dos Izbrisani). No momento em que este trabalho foi escrito, os principais problemas políticos revolviam em torno da reparação de 25.671 pessoas que foram oficialmente reconhecidas como Izbrisani. Em 30 de setembro de 2013, um acordo judicial de $40 €$ para cada mês de apagamento foi imediatamente rejeitado pelos advogados dos Izbrisani como sendo insuficiente.

4. Michelle Bachelet foi a primeira presidente a ser eleita na América do Sul. Como antiga opositora do General Pinochet e prisioneira política, esperava-se que ela focasse os direitos humanos, a justiça social e limitasse os poderes da polícia e agências de inteligência. A Revolução dos Pingüinos foi o primeiro evento radical com o qual teve que lidar como presidente.

\section{Referências}

AGAMBEN, G. Homo Sacer: sovereign power and bare life. Stanford, CA: Stanford University Press, 1995.

AITKEN, S. C. Putting Children in Their Place. Washington DC: Association of American Geographers Resource Publication Series. Boston: Edwards Bros, 1994.

. Geographies of Young People: the morally contested spaces of identity. London/ New York: Routledge, 2001. . The Awkward Spaces of Fathering. Aldershot: Ashgate, 2009. 
. The Ethnopoetics of Space: young people's engagement, activism and aesthetics. Aldershot: Ashgate, 2014.

. Reproducing Work and Revolution in Latin America. In.: SKELTON, T.; ABEBE, T.; WATERS, J. (Eds.). Geographies of Children and Young People. Labouring and Learning. Singapore: Springer Publications. [no prelo].

BACHELET, M. Address to the Nation. Chile, 21 May 2006. Disponível em http://www. presidencia.cl/documentos/mensaje-presidencial-archivos/21 mayo2006.pdf.

BAKAMJIAN, A. Chile's Penguin Revolution: Student Response to Incomplete Democratization, 2009. Disponível em http://stonecenter.tulane.edu/uploads/Bakamjian WEB-1312389920.pdf. Acesso em 13 fev. 2012.

BALIBAR, E. We, The People of Europe? Reflections on Transnational Citizenship. Princeton/Oxford: Princeton University Press, 2004.

BEZNEC, B. Once Upon a Struggle. In: ZORN, J.; ČEBRON, U. L. (Eds.) Once Upon an Erasure: from citizens to illegal residents in the Republic of Slovenia. Ljubljana: Študentska založba, 2008. p 15-18.

COLlEY, D.; AITKEN, S. C. The "Right to the Internet" is a Right to the City: public spheres, virtual commons and social movements online and in the street. Paper presented at the Annual Meetings of the Association of American Geographers, Los Angeles, april 2013.

CURTI, G.; CRAINE, J. W.; AITKEN, S. C. The Fight To Stay Put: social lessons through media imaginings of urban transformation and change. Stuttgart, Germany: Verlag Publishing, 2013. p. 9-18.

DALL'ORSO, A. R. C. Communication Strategies used by Chilean Teenagers in the Educational Movement of May 2006, 2011. Disponível em http://www.comminit.com/ en/ict-4-development/node/282977. Acesso em 21 fev. 2013.

DAVIDSON, J.; BONDI, L.; SMITH, M. Emotional Geographies. Aldershot: Ashgate, 2007.

DE CERTEAU, M. The Practice of Everyday Life. Berkeley, CA: The University of California Press, 1984.

DELEUZE, G.; GUATTARI, F. A Thousand Plateaus: Capitalism and Schizophrenia. London: The Athlone Press, 1988.

HARVEY, D. A Brief History of Neoliberalism. Oxford: Oxford University Press, 2005.

KALLIO, K.; HÄKLI, J. Are there politics in childhood? Space and Polity, v. 15, n. 1, p. 1-34, abr. 2011.

Children and Young People's Politics in Everyday Life. Space and Polity, Oxford, v. 17, n. 1, p. 1-15, abr. 2013.

KOGOVŠEK, N. The erasure as a violation of legally protected human rights. In: KOGOVŠEK, N. et al. (Eds). The Scars of the Erasure. Ljubljana, Slovenia: Peace Institute, 2010, p. 83-140. 
KUHELJ, A. Rise of xenophobic nationalism in Europe: A case of Slovenia. Communist and Post-Communist Studies, California, v. 44, n. 4, p. 271-282, dez. 2011.

LACLAU, E. New Reflections on the Revolution of Our Time. London: Verso, 1990.

LEFEBVRE, H. The Production of Space. Oxford: Blackwell, 1991. . Writings on Cities. Oxford: Blackwell, 1996.

LIPOVEC ČEBRON, U. "It Hits Your Nerves and All Kinds of Hell Break Loose". Psychological Distress of the Erased of Slovenia. Studies of Ethnography, Lucerne, v. 23, n. 1, p 259-82, dez. 2011.

MANDELC, D.; UČAKAR, T. Perforated Democracy: Disintegration, State-building, Europeanisation and the Erased of Slovenia. Revija Za Sociologiju, Zagreb, v. 41, p. 27-49, 2011.

MASSEY, D. For Space. London: Sage, 2005.

MARSHALL, D. J. 'All the Beautiful Things': Trauma, Aesthetics and the Politics of Palestinian Childhood. Space and Polity, Oxford, v. 17, n. 1, p. 53-73, abr. 2013.

MATTHEWS, H.; LIMB, M.; TAYLOR, M. Reclaiming the street: class, gender and public space. In.: HOLLOWAY, S.; VALENTINE, G. (Eds.) Children's Geographies: Living, Playing, Learning and Transforming Everyday Worlds. London and New York: Routledge, 2000. p. 63-79.

MOOSA-MITHA, M. A Difference-Centred Alternative to Theorization of Children's Citizenship Rights. Citizenship Studies, Oxford, v. 9, n. 4, p. 369-388, ago. 2005.

PISTOTNIK, S. The erasure as a testing ground for European migration policies, or pardon me, but your regulations have erased my status. In: KOGOVŠEK, N. et al. (Eds). The Scars of the Erasure. Ljubljana, Slovenia: Peace Institute, 2010. p 53- 78.

RANCIÈRE, J. The aesthetic dimension: Aesthetics, politics, knowledge. Critical Inquiry, Chicago, v. 36, n. 1, p. 1-19, fall 2009. 2010.

. The aesthetic heterotopia. Philosophy Today, Chicago, v. 54, n. supl., p. 15-25,

RAVITCH, D. Reign of Error: the hoax of the privatization movement and the danger to America's public school. New York: Alfred A. Knopf, 2013.

REEL, M. Chile's Student Activists: a course in democracy. The Washington Post, Washington DC, 5 nov. 2006.

THE PENGUIN REVOLUTION, 2006. Produção J. M. Sanhueza. YouTube Video, 2012. Disponível em https://www.youtube.com/watch?v=S5fTPqrTE5Q. Acesso em 01 feb. 2014.

STAEHELI, L.; ATTOH, K.; MITCHELL, D. Contested Engagements: youth and the politics of citizenship. Space and Polity, Oxford, v. 17, n. 1, p. 88-105, abr. 2013. 
ZDRAVKOVIĆ, L. The struggle against the denial of citizenship as a paradigm of emancipatory politics. In: KOGOVŠEK, N. et al. (Eds). The Scars of the Erasure. Ljubljana, Slovenia: Peace Institute, 2010. p. 257-77.

ŽIŽEK, S. On Violence. London: Profile Books, 2008. . Living in the End Times. London/New York: Verso, 2010.

ZORN, J. Registered as workers, erased as non-Slovenes: The transition period from the perspective of erased people. In: KOGOVŠEK, N. et al. (Eds). The Scars of the Erasure. Ljubljana, Slovenia: Peace Institute, 2010. p. 19-46.

ZORN, J.; LIPOVEC ČEBRON, U. Once Upon an Erasure: from citizens to illegal residents in the Republic of Slovenia. Ljubljana: Študentska založba, 2008.

Recebido em 17 de julho de 2014.

Aprovado em 24 de outubro de 2014. 